\title{
DENTAL FORENSICS: BITEMARK ANALYSIS
}

\author{
Elza I Auerkari \\ Department of Oral Biology, Faculty of Dentistry, University of Indonesia, \\ Salemba Raya No 4, Jakarta 10430 \\ E-mail : eauerkari@yahoo.com
}

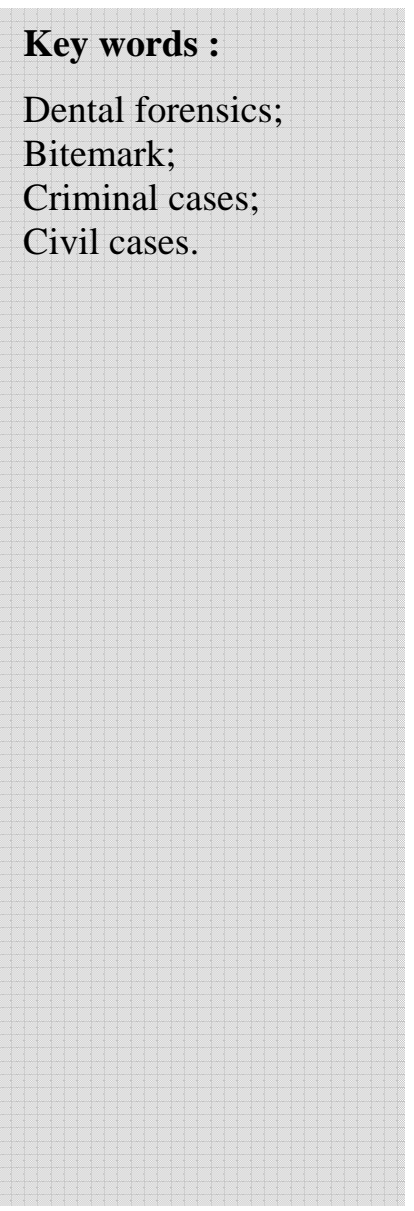

\begin{abstract}
Forensic odontology (dental forensics) can provide useful evidence in both criminal and civil cases, and therefore remains a part of the wider discipline of forensic science. As an example from the toolbox of forensic odontology, the practice and experience on bitemark analysis is reviewed here in brief. The principle of using visible bitemarks in crime victims or in other objects as evidence is fundamentally based on the observation that the detailed pattern of dental imprints tend to be practically unique for each individual. Therefore, finding such an imprint as a bitemark can bear a strong testimony that it was produced by the individual that has the matching dental pattern. However, the comparison of the observed bitemark and the suspected set of teeth will necessarily require human interpretation, and this is not infallible. Both technical challenges in the bitemarks and human errors in the interpretation are possible. To minimise such errors and to maximise the value of bitemark analysis, dedicated procedures and protocols have been developed, and the personnel taking care of the analysis need to be properly trained. In principle the action within the discipline should be conducted as in evidence-based dentristy, i.e. accepted procedures should have known error rates. Because of the involvement of human interpretation, even personal performance statistics may be required from legal expert statements. The requirements have been introduced largely due to cases where false convictions based on bitemark analysis have been overturned after DNA analysis.
\end{abstract}




\section{Introduction: bitemarks in forensic analysis}

Bitemarks have been routinely used as evidence in criminal and civil court cases for more than half a century [1]. The principle is similar as in case of e.g. fingerprint, ballistic and toolmark studies: the visually observable signs or marks at the scene are compared by an expert with the signs or marks left by the suspect object or person under comparable circumstances. Depending on the condition of the original bitemark at the scene, degree of clearly observable features in it, experience of the assessor and procedures applied, the comparisons to dental imprints of the available suspects can be a powerful source of evidence to either show common origin or exclude a suspect. This power of evidence largely stems from the fact that the details of human denture are practically unique to an individual, even able to discern between identical twins because the teeth are not only affected by inheritance but also by the highly personal life histories.

Provision of evidence from early bitemark analysis was not particularly concerned with the actual performance of the analysis, i.e. of the probability of correct or false identification. This is rapidly changing as experts is in many countries are needed to provide also evidence on the performance of the methods and personnel used [1]. For this purpose the experts, in this case mainly dentists involved, need to be well aware of the error sources to bitemark analysis and procedures to minimise the impact of errors. That significant error rates are at least possible in bitemark analysis is suggested by the fact that expert witnesses providing contradicting evidence statements are not uncommon [5].

Bitemarks are usually observed in skin, foodstuff or other materials found at the scene. The typical features to record for comparisons include rotation of teeth, displacement of teeth from the arch form, spacing between teeth, and anatomy of incision edges [6].

Three main issues are perceived as particularly important for the quality and outcome of bitemark analysis. These contentious issues are [3]

- methods of bitemark analysis

- uniqueness of human dentition (and related statistics)

- human skin as a material to register bitemarks.

Some of the known contentious features of these issues are shown in Table 1. The known potential weaknesses and corresponding typical countermeasures in bitemark analysis are listed in brief in Table 2 .

Table 1. Potential contentious features and countermeasures in bitemark analysis [3]

\begin{tabular}{lll}
\hline \multicolumn{1}{c}{ Issues in analysis } & \multicolumn{1}{c}{ Contentious features } & \multicolumn{1}{c}{ Measures / conclusions } \\
\hline $\begin{array}{l}\text { Methods of bitemark } \\
\text { analysis }\end{array}$ & - physical comparisons: severity & Use severity scale \\
& - biological techniques: DNA & Human or bacterial genotyping \\
$\begin{array}{l}\text { Uniqueness of human } \\
\text { dentition }\end{array}$ & $\begin{array}{l}\text { - evaluated from casts, not bites } \\
\text { Human skin as registration } \\
\text { material }\end{array}$ & Bitemarks may not be unique \\
\hline
\end{tabular}

Table 2. Potential weak points and countermeasures in bitemark analysis

\begin{tabular}{lll}
\hline \multicolumn{1}{c}{ Issues in analysis } & \multicolumn{1}{c}{ Weaknesses/difficulties } & \multicolumn{1}{c}{ Countermeasures } \\
\hline Sample in poor condition & $\begin{array}{l}\text { Lost detail, change in dimensions, } \\
\text { change in denture }\end{array}$ & $\begin{array}{l}\text { Sample preparation, image analysis, support from } \\
\text { archival records }\end{array}$ \\
Distortion in photo records & $\begin{array}{l}\text { Lack of scaling, deviant plane of } \\
\text { bitemark }\end{array}$ & $\begin{array}{l}\text { Image analysis, scale correction, support from } \\
\text { archival records }\end{array}$ \\
$\begin{array}{l}\text { Overall uncertainty } \\
\text { questioned }\end{array}$ & $\begin{array}{l}\text { Admissibility as evidence } \\
\text { in court }\end{array}$ & Quantification of uncertainty, statistical analysis \\
\hline
\end{tabular}


It is important to remember also that unclear bitemarks may not become supporting evidence even if the correct source of the bitemark has been found. In such cases it must be admitted that the bitemark analysis is inconclusive, and the conclusion such as court decision (if not acquittal) must be based on other evidence. The requirements on expert performance have been introduced largely due to cases where false convictions based on bitemark analysis have been overturned after DNA analysis $[1,3,4]$. Below, the available evidence of the performance of bitemark analysis is considered in brief.

\section{Performance of bitemark analysis}

Several statistical assessments have been made on bitemark analysis. Early studies started with comparison of bitemarks under rather ideal conditions, for example the dentures with bitemarks in wax, achieving 99\% agreement between experienced examiners. However, when using animal skin to reproduce the bitemarks, the agreement rate dropped to $72 \%$, and it was suggested that the rate of agreement would be similar in case of human skin [7].

A more recent assessment of 32 experienced bitemark analysts applied four photographs of bitemarks (three from skin of deceased individuals, one from cheese) with dental casts of four known culprits and three randomly selected dental patients [2]. Each expert was asked to express their degree of confidence that the case was a bitemark, then their view of the evidence value of the case, and finally their opinion on the strength of the link between each bitemark case and the seven dental casts, using a seven-point scale from 1) reasonable medical certainty, 2) probable, 3) possible, 4) improbable, 5) incompatible, 6) inconclusive, and 7) non-diagnostic. The linking was compared with the actual pairing of the bitemark and dental cast, and the results were calculated in terms of the receiver operating characteristics (ROC) curve (Fig 1a). In this case the overall result suggests that the diagnostic accuracy was 86\% (area under the ROC curve).
In comparison, an earlier ROC analysis suggests rather worse performance [5]. In this study, assessment of 50 actual photographic bitemarks was made by 109 assessors that varied from senior and junior forensic experts to general practitioners, dental students, police officers and social workers. The subjects were only asked to give their opinion of whether the bitemark was made by an adult of a child, on the following scale: 1) certain, 2) fairly certain, 3 ) slightly more likely that it was made by an adult, 4) unsure; and 5) slightly more likely, 6) fairly certain, 7) certain that it was made by a child. The results are shown in Fig 1b. Even the best performers, i.e. senior forensic experts had a diagnostic accuracy of only $69 \%$ [5].

In conclusion, the rate of false positives is relatively high and it appears therefore not appropriate to use bitemark analysis with similar confidence as e.g. DNA analysis $[4,8]$. On the other hand, in favourable cases bitemarks can provide useful evidence. Their discerning power is best when they are fresh and clear, made on materials such as foodstuffs where most distinct imprint is retained, and when the dental pattern of the bitemark includes very clear and sufficiently complex features such as combinations of missing and protruding/misaligning teeth. Equally important is however that the bitemark evidence is appropriately processed by an experienced assessor. Obviously for positive identification it is necessary that the owner of the teeth (or other evidence like his/her dental casts) must be at hand for comparison, but even when this turns out not to be the case, bitemark evidence may serve to exclude a suspect.

Because the bitemark will also contain saliva and possibly other biologic matter from the biting individual, at least in case of fresh bitemarks such material can be collected and used for DNA analysis. If sampling is successful, the bitemark then can provide even stronger indication of the person that made the bitemark. Limitations include the additional cost of DNA analysis and varying sensitivity due to sampling and degradation of DNA in case of older bitemarks. 


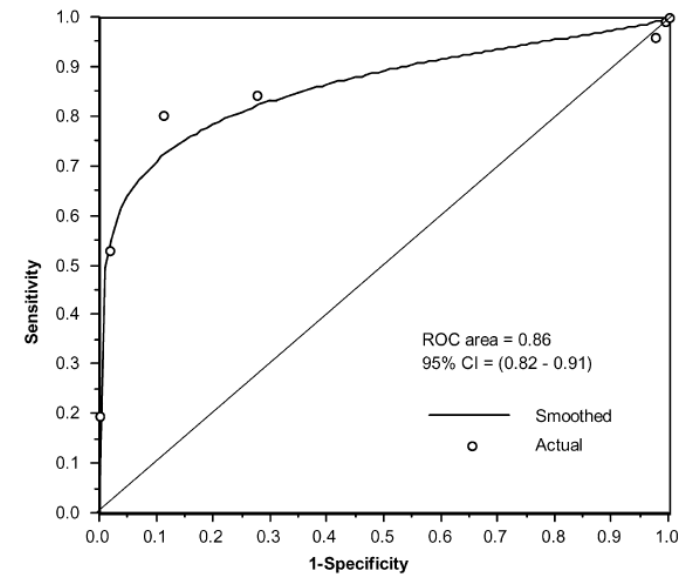

\begin{tabular}{lrl} 
Rating & \multicolumn{2}{c}{ Correct dentition } \\
\cline { 2 - 3 } & $n$ & TPF (sensitivity) \\
\hline Reasonable medical certainty & 25 & 0.1953 \\
Probable & 43 & 0.5312 \\
Possible & 35 & 0.8046 \\
Improbable & 5 & 0.8437 \\
Incompatible & 15 & 0.9609 \\
Inconclusive & 4 & 0.9922 \\
Non-diagnostic & 1 & 1.0000 \\
Total & 128 &
\end{tabular}

a)
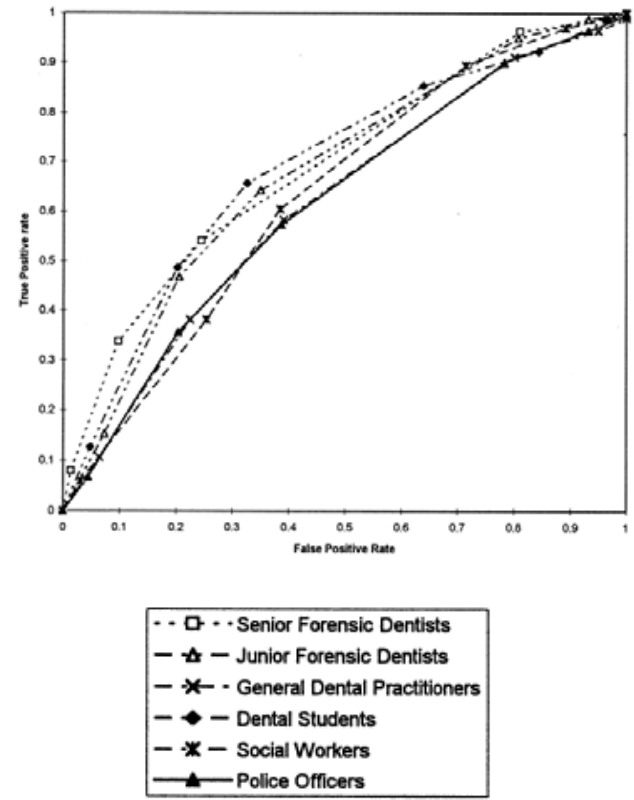

b)

Fig 1. ROC curves for bitemark analysis: a) expert analysis and linking between bitemark photographs and dental casts [2]; b) analysis by different levels of experts when only assessing whether a bitemark was produced by adult of child [5]

\section{Conclusions}

The power of bitemark analysis from samples in poor condition (e.g. from aged skin samples) may sometimes be questionable because of loss of visible details, dimensional changes, and also because of possible loss of discerning detail due to orthodontic and other dental treatment. However, in general the pitfalls of bitemark analysis can be effectively countered by sticking to tested procedures and sound expertise in was that can prove the track record. In addition, it is very important also to be able to declare a case as inconclusive, as the bitemark evidence to a criminal or civil cases can carry significant uncertainty. However, it is equally important that the expert is able to show evidence of the expected uncertainty so that decisions can be based on fair judgement of the evidence. The requirements on expert performance have been introduced largely due to cases where false convictions based on bitemark analysis have been overturned after DNA analysis.

\section{References}

1. Bowers C M, Johansen R J. Digital rectification and resizing correction of photographic bite mark evidence. Forensic Science Communications 2001; vol 3 (3): http://www.fbi.gov/hq/lab/fsc/backissu/july2001 index.htm

2. Arheart K L, Pretty, I A. Results of the $4^{\text {th }}$ ABFO bitemark workshop-1999. Forensic Science International 2001; 124: 104-111.

3. Pretty I A. The barriers to achieving an evidence base for bitemark analysis. Forensic Science International 2006; 159S: S110-S120.

4. Bowers C M. Problem-based analysis of bitemark misidentifications: the role of DNA. Forensic Science International 2006;159S: S104-S109 
5. Whittaker D K, Brickley M R, Evans L. A comparison of the ability of experts and nonexperts to differentiate between adult and child human bite marks using receiver operating characteristic (ROC) analysis. Forensic Science International 1998;92: 11-20.

6. Kouble R F, Craig G T. A survey of the incidence of missing anterior teeth: potential value in bite mark analysis. Science and Justice 2007;47: 19-23

7. Whittaker D K. Some laboratory studies on the accuracy of bitemark comparison. International Dental Journal 25 (1975), 166-171

8. Elza Auerkari. Recent Trends in Dental Forensics. Indonesian $\mathrm{J}$ of Legal \& Forensic Sciences 2008; 1(1):5-12. 